\title{
Estética do cotidiano: experiência e produção de saberes na formação docente
}

\author{
Luciana Haddad Ferreira* \\ Raul Cabral França* \\ Beatriz Vito Vieira*
}

\section{Resumo}

Toma-se como objeto de estudo e reflexão, neste trabalho, a articulação possível entre o cotidiano da escola e as experiências estéticas que possibilitam uma formação docente sensível e integradora. Partindo de uma perspectiva histórico-cultural, questiona-se a desvinculação entre a produção de saberes e a prática de ensinar, discutindo a formação de professores e propondo que esta se dá também no cotidiano da escola, que pode ser palco de experiências sensibilizadoras e transformadoras. Para tal, afirma-se que é necessário ao professor uma atitude estética diante da prática, análoga à do artesão, que alia o conhecimento técnico de seu ofício aos saberes sensíveis advindos da experiência, atento às sutilezas daquilo que vivencia e permeável ao encanto, aprendendo e ensinando pela relação com o outro. Considerando que, dessa forma, o cotidiano da escola torna-se uma instância privilegiada para a produção de saberes sobre o fazer docente, que não poderiam ser construídos de outra maneira, busca-se demonstrar que esse professor, compreendendo os alunos como portadores de histórias e singularidades, poderá constituir-se em propositor de experiências significativas, potentes para auxiliá-los na produção de sentidos, em uma relação autenticamente formativa.

Palavras-chave: Cotidiano. Educação estética. Formação de professores.

\section{Introdução: uma conversa sobre cotidiano, estética e formação}

Houve um tempo, como nos lembra Geraldi (2010), em que aquele que reflete sobre as coisas e aquele que as ensina necessariamente se fundiam na mesma figura. Assim, o conhecimento produzido pelos sábios era difundido por eles próprios

Recebido: 05/12/2015 - Aprovado: 11/03/2016

http://dx.doi.org/10.5335/rep.v23i1.6357

Doutora em Educação. Pesquisadora do Grupo de Estudos e Pesquisas em Educação Continuada (Gepec) da Universidade Estadual de Campinas - Unicamp. E-mail: haddad.nana@gmail.com

* Membro do Programa de Pós-Graduação em Educação da Faculdade de Educação da Unicamp, integrante do Gepec/Unicamp. E-mail: raulfranca@gmail.com

**** Pedagoga, graduada pela Faculdade de Educação da Unicamp, membro do Gepec/Unicamp. E-mail: biavitov@gmail.com 
entre seus discípulos. Sabemos também que, por vezes, o papel que tem hoje o professor remonta ao mercantilismo, período em que as transformações históricas na divisão social do trabalho levaram à dissociação entre as funções de elaborar o conhecimento e de ensinar. À maneira de compositores, os especialistas tornam-se responsáveis pela pesquisa que produz o conhecimento e pela sistematização, em forma de materiais didáticos, do saber existente. À maneira de intérpretes, os professores são incumbidos de ler e executar corretamente a "partitura" - cartilhas, apostilas, materiais pedagógicos - que outro compôs. Propomos aqui uma discussão sobre cotidiano, estética e formação, considerando a necessidade de lançar um olhar crítico e propositivo às concepções atualmente observadas da docência, tendo em vista como este profissional se constitui ao articular tempos, espaços e percepções vividas.

Para melhor compreender o campo de aprendizado profissional, assumindo a necessidade da formação continuada de professores e partindo das contribuições da teoria histórico-cultural, entendemos o professor como indivíduo que está em constante aprendizado e que se forma através da relação que estabelece com o outro e com o meio. Em seus estudos direcionados aos processos de aprendizado e à educação, Vigotski (2001) enfatiza a relevância da cultura para a formação, pois é por meio das relações e produções humanas que atribuímos significado às coisas e elaboramos conhecimento. Ao assumir tal concepção, marcamos posição com relação ao modo de ver e compreender a formação continuada de professores.

Afirmar que o cotidiano escolar pode ser palco de experiências transformadoras e sensíveis para o docente representa uma ruptura com o modelo compositor-intérprete. Descaracteriza a escola como lugar exclusivo de reprodução e leva em consideração a produção de novos saberes a partir da historicidade e das singularidades do professor na relação com seus alunos e com os parceiros de trabalho. Recupera a ideia de sermos portadores de saberes advindos das próprias vivências e da reflexão ocorrida a partir delas, centrando na mesma figura o pesquisador e o professor.

Propomo-nos, então, a fazer uma análise aprofundada a respeito da articulação possível entre formação docente e os saberes profissionais elaborados e em circulação no cotidiano da escola. Tal relação passa, necessariamente, pelos domínios da estética, uma vez que a vivência da sala de aula possibilita ao professor conhecer uma dimensão sensível de seu trabalho, pouco percebida pelo olhar pautado apenas nos pressupostos técnicos do ofício.

Entendemos o trabalho do professor como exercício sensível e essencialmente estético, que pode ser compreendido em analogia com a figura do artesão. Este último, detentor de um bom domínio técnico de suas ferramentas de trabalho, é capaz de utilizá-las com autonomia para realizar seu ofício, lançando mão dos conheci- 
mentos necessários para manter a originalidade e a totalidade de sua atuação. Cada dia de trabalho do artesão mostra-se único e inovador, pois suas experiências contribuem para que ele modifique seu próprio modo de fazer, criando novas possibilidades e compartilhando seus saberes com os aprendizes e outros mestres. A característica artesanal do trabalho docente reside na sua necessidade de colocar-se inteiro na sala de aula e de olhar para a própria prática como obra inacabada, que deve sempre ser objeto de sua própria reflexão.

Ao abordar a concepção de estética, referimo-nos aos saberes sensíveis que constituem as experiências ou, ainda, o conhecimento obtido por meio dos sentidos, que nos permite melhor observar e atuar cotidianamente. Estética pode ser compreendida, então, como a faculdade humana de percepção sensória, que articula a cultura com as individualidades, de modo a criar representações, emoções e sentidos que nos são próprios. Diante dos desafios da docência, uma atitude estética é aquela que compreende a ação educativa como emancipadora, que mobiliza o indivíduo e o leva a agir propositivamente. É a estética que permite entender as relações formativas como atos de produção de sentidos, verdadeiros encontros entre pessoas, que prezam pela qualidade das experiências possibilitadas. Assim, pela estética é possível aprender e ensinar a lidar consigo mesmo e com os outros, compreender-se como parte de determinada cultura, perceber que as ações tomadas ocasionam mudanças na sociedade e no convívio com os demais (FERREIRA, 2014).

Afirmamos, então, que as experiências estéticas vivenciadas pelos próprios professores em momentos de formação são potencializadoras desses processos reflexivos. Considerando que tais situações vividas são apreendidas de modo a alterar as nossas imagens, ações e emoções, dizemos aqui da necessidade de levar em conta esses aspectos de modo intencional e efetivo, de forma que o profissional perceba-se dotado de habilidades expressivas, de saberes relevantes ao seu ofício e de atitudes relevantes para a prática educativa. É como se o intérprete, outrora se limitando a tocar conforme a partitura, passasse a criar novos arranjos para conferir à música a autenticidade que a interpretação lhe pede. Da mesma maneira, 0 professor será capaz de colocar-se frente aos desafios de modo consciente e integrador, tendo maior ciência de suas capacidades e necessidades de aperfeiçoamento.

Uma proposta formativa pautada na proposição de experiências sensíveis intensifica a apropriação dos saberes à disposição do professor e o torna capaz de ressignificar tais conceitos de acordo com outras necessidades que possa vir a perceber, ampliando o conhecimento de mundo e de si mesmo e favorecendo seu pensamento crítico. A formação estética preza, neste sentido, pela constituição de um profissional que percebe a si e ao outro como membros de uma sociedade, cons- 
tituídos pelas heranças históricas e culturais, mas ao mesmo tempo dotados de um modo próprio de ver e compreender sua ação no mundo.

Concordando com Tardif (2002), consideramos o saber docente como uma rede de múltiplas articulações formada pelos sentidos atribuídos a saberes advindos da formação acadêmica e pelas experiências vivenciadas no cotidiano. É o conhecimento mobilizado e ressignificado em diálogo com as vivências e com os pressupostos que guiam suas decisões e ações. Nesse sentido, a relação do professor com os saberes não se resume apenas à apropriação e à transmissão dos conteúdos previamente definidos. $\mathrm{O}$ saber docente pode ser compreendido em íntima relação com o trabalho desenvolvido na escola e na sala de aula, pois, apesar do necessário domínio técnico do conhecimento inerente ao seu ofício, sua utilização se dá em função do seu trabalho e das situações incertas vividas cotidianamente (PINA; SADALLA, 2007).

Dessa maneira, a proposta aqui apresentada narra uma forma de ensino que preza pela inteireza dos indivíduos e pela riqueza das relações estabelecidas em um espaço coletivo. Falamos de ensinar e aprender a docência com o próprio exercício da docência, preservando a alteridade, pois esta carrega as marcas históricas dos sujeitos, e promovendo a igualdade quando esta promove oportunidade de aprendizagem e convivência entre todos.

\section{0 cotidiano é formador: formação reflexiva na escola}

Começamos a trabalhar poesia no início do mês, estão empolgados, percebi que gostam bastante de ler. Hoje passei uma poesia do Sérgio Caparelli, lemos, falamos sobre ela. [...] Escolhi algumas palavras e pedi que escrevessem três palavras que rimassem com elas. Passado um tempinho, H. chegou à mesa e me entregou o caderno. [...] Comecei a olhar as rimas, uma das palavras para rimar era acordei, ele escreveu: sonhei, respirei, ratei. Perguntei a ele o que era aquilo que ele havia escrito e, com o sorriso delicioso de sempre, me respondeu: ah, quer dizer que eu virei um rato, então eu ratei! Rindo, falei que não podia, que aquela palavra não existia. Nossa! Se arrependimento matasse... Desatou a falar: Professora, claro que pode, é uma fantasia, é a minha imaginação! Você falou pra minha mãe outro dia que a minha imaginação era boa, agora tá dizendo que é ruim? [...] Bom, nessa hora resolvi tirar o time. Falei que tudo bem, estava certo. Com o mesmo sorriso, foi caminhando até a rede, no meio do caminho gritou: Prô, quando eu for escrever a poesia vou fazer bem linda, não fica triste não! ${ }^{1}$ [...] (CAMPOS, 2015, p. 27-28, grifo do autor).

A narrativa pedagógica de Cristina Campos (2015) nos convida a pensar sobre a diversidade das relações e dos saberes existentes no espaço da escola. Ao falar sobre a maneira como percebe seus alunos e os incentiva a criar, colocando suas próprias certezas em cheque, a professora afirma o cotidiano como espaço e tempo da formação docente, pois reflete a partir de suas práticas e as modifica, em constante movimento de busca e elaboração de conhecimento. 
Percebemos, então, que o cotidiano é fonte de saberes para os professores, pois os embates vividos na sala de aula possibilitam sua reflexividade e os levam a buscar saberes que ainda não possuem, para poderem resolver os dilemas da prática. Sá-Chaves (2002) aponta que a formação reflexiva permite ao profissional ajustar-se criativamente perante as zonas de indefinição da prática (compostas por questões não previstas, atitudes inesperadas e variáveis desconhecidas que permeiam o relacionamento entre pessoas em um ambiente de aprendizado). Nesse mesmo sentido, Alarcão afirma que a prática da reflexão nos "relança para os valores do humano, que insistentemente teimam em vir respirar a tona da água num mundo vincadamente poluído pelo racionalismo técnico" (2010, p. 12). Desse modo, encaramos a atuação profissional como exercício sensível e reflexivo que é composto por contribuições dos campos teóricos, técnicos e simbólicos.

Cristina Campos (2015) nos ensina ainda, por meio de sua narrativa, que refletir sobre a prática é exercício que se faz com o outro: ao acolher as inquietações de seu aluno e mostrar-se sensível ao que ele mostra como importante, ela passa a observar sua aula e as propostas didáticas de outra maneira. Isso posto, fica evidente que o ensino reflexivo pressupõe diálogo e construção coletiva. Além da própria sala de aula e das relações estabelecidas com os alunos, os momentos de trabalho com os pares (como as reuniões pedagógicas, os encontros de estudos) são fundamentais para a promoção da identidade das equipes de trabalho e também para o desenvolvimento dos processos reflexivos dos professores. No entanto, há que se considerar como interlocutores não apenas os seus parceiros diretos de trabalho - os outros professores -, mas também todos os profissionais envolvidos com o ambiente educativo. Evidencia-se a importância do coletivo de trabalho na escola, em especial do coordenador pedagógico, para a formação e reflexão no cotidiano. Esse vínculo torna potente o diálogo, a cumplicidade e a construção compartilhada de imagens da docência.

O professor, dessa maneira, encontra acolhimento para seus anseios, estímulo para suas investigações, apontamentos e possibilidades para melhor avançar sobre o campo teórico e diálogo para suas produções intelectuais. Assim, percebe a razão de suas ações, vislumbra o desencadeamento de consequências e reações provenientes de seu trabalho, age reflexivamente, rejeitando crenças cegas ou a mera transposição de conteúdos dados a priori e de forma estanque.

Os trabalhos de Schön (2000) insistem em revelar a necessidade de estreitamento no modo como percebemos e concebemos a relação entre teoria e prática, afirmando que as hipóteses teóricas devem ser cotejadas cotidianamente, no espaço de trabalho. As escolas podem, assim, planejar situações de práticas e reflexões coletivas, promovendo discussões nas quais se aprende a partir das interações que 
são estabelecidas, ou seja, na relação com o outro. Vale ressaltar que buscar a fundamentação teórica não significa ir atrás do auxílio de teorias descontextualizadas da prática cotidiana, mas desvelar quais teorias subsidiam a tomada de decisão dos professores. É movimento de busca nos sistemas teóricos dos autores com quem se compartilha princípios e pressupostos para fundamentar as práticas cotidianas. Autores como Sá-Chaves (2002) e Sadalla (1998) avançam na questão ao apontar para a necessidade de uma formação na qual o professor seja capaz de articular com propriedade o conhecimento à prática educativa, de maneira reflexiva.

A complementaridade entre pensar e sentir se deixa transparecer ao reconhecermos que o conhecimento inteligível amplia a capacidade sensível e vice-versa, pois, como afirma Duarte Jr. (2001), pensar/sentir a respeito de algo de modo profundo e reflexivo leva a colocarmo-nos de modo diferente frente às situações cotidianas e nos abrir a novas experiências. Por esse motivo, o exercício de reflexão docente constitui-se em elemento de grande valor na construção da prática educativa e não pode ser desvinculado da experiência estética. A relação entre teoria e prática vai além de transpor os saberes eruditos à prática pedagógica, pois o conhecimento só é construído por meio da percepção sensível e da reflexão do professor sobre seu trabalho e sobre a realidade em que está inserido, com seu olhar único de quem vive e percebe-se totalmente dentro do processo educativo.

Contida na narrativa de Cristina Campos, uma importante premissa da formação docente encontra ressonância na proposta por nós defendida: o educador não pode dobrar-se diante das prescrições postas externamente, mas também não deve ignorá-las. Pode servir-se do que está posto, em articulação e diálogo com suas crenças e teorias, em busca da criação de uma prática autoral e dotada de estética pessoal.

\section{0 cotidiano é sensibilizador: educação estética na escola}

Então, depois de um sonoro bom dia, começava a leitura. Lia para eles as mais diversas histórias. Imitava vozes, criava expectativas, deixava suspense, pedia que inventassem outros desfechos. [...] Menino também estava lá. Mas ao contrário das outras crianças, não ia para seu lugar, andava para lá e para cá. [...] Então, num daqueles dias, nem mais nem menos agitado e barulhento, depois de nosso sonoro bom dia, menino se dirigiu à estante, pegou o livro laranja [...]. Postou-se a frente da sala, com o livro desajeitadamente aberto. Esperou que todos olhassem e... leu. Leu para mim e para todos os colegas. Balbuciou palavras, fez expressões de espanto, riu, mostrou figuras. A cada gesto, olhava em minha direção. Leu sem saber ler (FERNANDES, 2014, p. 60-62).

Márcia Fernandes escolheu narrar sua experiência como professora por meio de linguagem poética. Seu modo de tecer com palavras nos aproxima desse menino, 
ao mesmo tempo em que sugere ser ele um entre tantos meninos que vemos na escola. A professora faz uma escolha ao trazer para seu registro o menino-possibilidade, menino-potência, menino-surpresa. Denuncia que o cotidiano é formador quando nos mostramos abertos para isso, recusando os meros afazeres para, junto com o grupo, viver tudo o que se tem a fazer. Ao relatar sua percepção do aluno que, à sua maneira, começa a ler, a professora revisita suas próprias concepções de aluno e professor, confronta suas crenças com aquilo que vive, e demonstra compreender que a relação estabelecida cotidianamente com seu grupo a faz alargar sensivelmente o seu conhecimento a respeito da alfabetização, das práticas pedagógicas e do processo de aprendizado dos sujeitos. É na sala de aula que seus saberes fazem sentido. Assim, a autora se coloca em atitude investigativa diante do grupo de alunos e, nesse caso especialmente, do menino. Ela não toma as ações do outro como respostas às suas investidas, nem busca justificar teoricamente os comportamentos observados. Ao contrário, olha para o menino, busca compreender o modo como ele se relaciona com o conhecimento e vê nele / com ele / a partir dele como deve proceder para que a aula seja uma experiência significativa. É a docência entrelaçada com a pesquisa e a reflexão.

Ao afirmar que a investigação realizada pelos professores expressa a articulação dos saberes culturalmente difundidos com um ponto de vista próprio (ZEICHNER, 1993), reafirmamos a ideia de que os docentes podem olhar para seu trabalho e para o cenário educativo contemplando suas inúmeras possibilidades e percebendo as subjetividades e potencialidades dele advindas. $\mathrm{O}$ desenvolvimento deste olhar sensível e a obtenção desta visão mais abrangente da educação são conquistas da experiência estética, assim como Márcia Fernandes nos convida a experimentar por meio de seu registro.

A professora nos ensina que o ato formativo ocorre estando junto com o outro, vivenciando com ele os momentos cotidianos e fazendo com que cada vivência se configure em experiências repletas de sentido estético, prático e cognitivo, convidando os sentidos a uma nova construção. Desse modo, as reflexões de Márcia deixam transparecer que, em uma concepção de educação sensível, o professor tem como função, além de mediar as relações dos alunos com o conhecimento, promover a apreciação estética e o encantamento com o mundo, desenvolvendo a sensibilidade também de seus aprendizes.

No contexto formativo, percebemos que os professores utilizam sua percepção estética quando realizam sua função com domínio técnico aliado à sensibilidade, que permite compreender os contextos particulares de sua sala de aula e de sua realidade, tornando possíveis a reflexão e o ajustamento criativo a situações inusitadas com as quais se depara. Ainda, é essa sensibilidade que confere ao docente a 
visão de que cada aprendizado compartilhado é uma grande lição, e que cada aula - fruto de seu trabalho - é um acontecimento único e irrepetível.

A formação sensível do professor ocorre no convívio cotidiano da escola, tanto em sala de aula, com seus alunos, como em outros contextos. Tal qual o movimento do artesão, o professor aprende a fazer a docência no compartilhamento de seu trabalho com parceiros mais experientes e também ao ensinar seus saberes aos iniciantes. Não aprende apenas na troca de informações, mas no convívio com o outro e no exercício da coletividade.

As práticas expressivas que valorizam os processos criativos e momentos de fruição poética também precisam ganhar espaço nas discussões mais recentes e nas salas de aula. Esse movimento, fundamental para a formação dos professores, possibilita encontro direto com a cultura, concilia os saberes eruditos com o popular, as inovações com a tradição, o pessoal com o coletivo, o particular com o comum. O professor forma-se em movimento sincrônico de descoberta e construção de novos saberes, olhando para a sala de aula - e para si próprio - como se nunca antes a tivesse visto, maravilhando-se e ao mesmo tempo permitindo-se apreender toda a realidade com os seus sentidos.

Nesta direção, a experiência vivida por Márcia e seu menino fazem ecoar o entrelaçamento de culturas e saberes no espaço da escola. Concordando com tal compreensão, Ferreira (2014) afirma que os sentidos, a imaginação e a reinvenção estão diretamente relacionados à ideia do inacabamento do ser humano e, com isso, à história aberta como possibilidade. É concepção fundamental na formação docente que considera e busca o protagonismo nas ações. Em contato com a sensibilidade e em busca de seus ideais educativos, torna-se capaz de perceber o mundo como realidade em constante transformação, em que sua atuação provoca alterações nos demais sujeitos. Paulo Freire, ao dizer da estética na educação, defende:

É preciso ousar, no sentido pleno desta palavra, para falar em amor sem temer ser chamado de piegas, de meloso, de a-científico, senão de anticientífico. É preciso ousar para dizer cientificamente que estudamos, aprendemos, ensinamos, conhecemos com nosso corpo inteiro. Com sentimentos, com as emoções, com os desejos, com os medos, com as dúvidas, com a paixão e também com a razão crítica. Jamais com esta apenas. É preciso ousar para jamais dicotomizar o cognitivo do emocional (1993, p. 10).

Inspirados por Freire, falamos sim da beleza de ensinar/aprender, defendendo as práticas de apaixonamento dos professores por sua ação e sugerindo que olhem com propriedade para o cotidiano. A atuação sensível do professor junto a seu grupo é, por si, performance imbuída de estética, quando carregada de percepção ética e de consciência de sua condição. Defendemos, então, uma formação sensível, ressaltando que é necessário mobilizar-se diante do vivido, implicar-se nos processos 
e buscar brechas, novos caminhos, em contrapartida às dificuldades e aos dilemas percebidos, e questionar as práticas e as próprias condições de trabalho (FERREIRA, 2014).

A vivência estética implica um olhar apurado e curioso para a realidade, buscando perceber-se além da superficialidade e das concepções já dadas. É maneira de voltar-se ao mundo com a atenção e a simplicidade de quem busca apreender novos sentidos, conhecê-lo de outra maneira. Márcia Fernandes mostra que tal movimento só é possível ao considerar as perspectivas das crianças e dos outros sujeitos envolvidos na dinâmica da escola. É nessa atitude diante do vivido que residem a beleza e o sentimento de contemplação. "A percepção estética significa não apenas relançar os olhos para algo, mas atentar a ele, fitá-lo, perscrutá-lo - em suma, vê-lo realmente" (DEWEY, 2010, p. 33). É a busca por outras possibilidades de significação para o que já parece familiar, um olhar que tenta despir-se de marcas para poder conhecer e fazer outras marcas.

\section{0 cotidiano é mobilizador: produção de saberes na escola}

Íamos ouvir uma das histórias de Sherazade: Alibabá e os 40 ladrões. [...] Quando a história estava em seu clímax, parei. [...] Propus que cada um escrevesse e desenhasse o que acreditava que fosse acontecer. [...] João Guilherme, um menino que já escrevia alfabeticamente, muito concentrado, sentou-se à mesa e pôs-se a trabalhar. [...] À medida que as crianças trabalhavam, eu caminhava pela sala [...]. Todavia, ao chegar perto de João Guilherme, levei um grande susto: como era possível que uma criança que já escrevia alfabeticamente tivesse "regredido" na escrita? [...] Mas, por outro lado, ecoava o aprendido ao longo de minha formação, com meus pares e com minhas próprias crianças: como diagnosticar o menino sem sequer ouvi-lo? [...] Por isso, dirigi-me a João Guilherme: — João, você pode ler pra mim o que escreveu? Do jeito que ta escrito, eu não consigo ler sozinho... [...] João Guilherme foi ao meu socorro: - Está escrito TACAPAVVVOZONOCADX... - leu letra por letra e completou com triunfo: — É a fala do irmão do Alibabá, tio, quando ele ficou preso na caverna! Ele ficou tão nervoso que não conseguiu lembrar a palavra mágica. [...] A solução encontrada por João era perfeita! Mas de que maneira essa mesma produção seria compreendida se eu não houvesse [...] realizado o exercício de escutá-lo no que ele tinha a dizer? [...] (RIBEIRO, 2015, p. 106-109).

Depararmo-nos com a ideia de que aprendemos com a nossa experiência é algo comum. Porém, em alguns contextos, a prática da reflexão é entendida como fazer um balanço: ao final de um período, evento ou projeto, os envolvidos realizam a avaliação dos resultados, geralmente comparando-os ao planejamento inicial, verificando erros e acertos no intuito de aprimorar a prática no trabalho seguinte. Um conceito de reflexão, portanto, que entende o trabalho configurado em momentos de planejar, momentos de atuar e momentos de avaliar. Sem dúvida, tais momentos podem vir a ser valiosas oportunidades de aprendizado sobre a prática escolar; 
porém, o tipo de compreensão que se pode adquirir nessas ocasiões representa a totalidade da prática docente? Esgota os saberes que a escola pode produzir?

Entendemos que as possibilidades de o professor atuar e conhecer sua própria prática se estendem muito além, e por isso defendemos o cotidiano como uma instância privilegiada para a produção de saberes na escola. Embora reconhecendo a importância de uma rotina que inclua planejamento e avaliação periódica, é necessário discutir os pontos de contato e as diferenças entre a proposta de que o professor se coloque sensível e reflexivamente diante do cotidiano, apresentada neste artigo, e a ideia de que refletir é fazer balanços periódicos - em período diário, bimestral, anual ou outro qualquer. Para isso, iremos dialogar com as lições trazidas pela narrativa pedagógica do professor Tiago Ribeiro.

Os momentos de planejar, atuar e avaliar pertencem a um tempo que é o dos programas, dos relatórios, dos cronogramas. No mesmo espaço - a escola -, se desenrola também, concomitantemente, outro tipo de tempo: o das relações, das vivências, das curiosidades e dos saberes. É a esse outro tempo que pertencem o imaginário das crianças, as indagações dos jovens, os afetos, as experiências verdadeiramente significativas que se constituem em saberes que transformam. Tiago nos ensina, ao compartilhar sua experiência, que é preciso se permitir afetar pelos acontecimentos da vida na escola. Sem a ingenuidade de entregar-se ao mero deslumbramento diante dos fatos cotidianos, desvela a importância de não passar indiferente pelo que é vivido, abrindo-se para experiências sensíveis. E faz isso demonstrando compreender a relação indissociável entre teoria e prática, ao buscar em seu repertório de conhecimentos os critérios para interpretar as situações e decidir sobre a intervenção a ser feita.

À medida que as crianças trabalhavam, eu caminhava pela sala, observando e perguntando quem precisava de ajuda, pois um dos princípios perseguidos por mim, com as crianças, é o de que a ajuda amplia as possibilidades de saber, atua em seus conhecimentos prospectivos, de maneira que, conforme nos ensinou Vygotsky (1994), hoje, através da ajuda, podemos fazer o que amanhã seremos capazes de fazer sozinhos (RIBEIRO, 2015, p. 107-108).

Ao perceber-se desafiado por uma produção de seu aluno, muitas cogitações lhe tomaram o pensamento. No primeiro momento, sua reação foi de preocupação; a escrita indecifrável do aluno parecia um sinal de regressão em relação à capacidade que ele já demonstrava ter, o que, teoricamente, não deveria acontecer. "Por que esse monte de letras sem sentido? Foram muitas as hipóteses que passaram pela minha cabeça!" (2015 p. 108), escreve Tiago, revelando sua ansiedade em encontrar uma explicação para o que estava vendo. Por colocar-se sensivelmente no cotidiano, o mesmo interesse em articular a prática à teoria, que mobilizou o professor a buscar formas de interpretar o suposto problema, rapidamente o levou, no 
momento seguinte, a suspeitar dos diagnósticos precipitados que estava prestes a formar. Tiago conta que havia aprendido, com seus pares e com os próprios alunos, que estaria cometendo um erro se julgasse o pensamento de uma criança sem antes ouvi-la; então, se perguntou: "[...] que concepção temos de infância quando somos nós, adultos, os que temos a palavra correta e final sobre as crianças?" (2015, p. 108). A reflexividade que o cotidiano propicia - esta de que falamos - só pode, como se percebe, acontecer quando estamos cotidianamente nos perguntando.

$\mathrm{Na}$ reflexão que se restringe aos balanços periódicos, pode-se até dizer que as figuras do compositor e do intérprete existem no mesmo professor, uma vez que é ele próprio que planeja a ação, atua e avalia os resultados. Porém, não existem ao mesmo tempo, combinadas. Os momentos em que compositor e intérprete entram e saem de cena estão bem demarcados. Na atitude estética diante do cotidiano, por sua vez, não existe um momento da reflexão ao fim do período pelo qual se espera para enfim pensar sobre as lições aprendidas com a prática. Afinal, consideramos que as decisões pedagógicas importantes não são apenas aquelas que, em uma instância mais estrutural, definem aspectos como currículo, regras disciplinares, escolha do material didático e dos métodos de avaliação.

A prática do professor o coloca diante de inúmeras situações de decisão diariamente, e é o olhar sensível que o permite perceber o quão capital cada uma dessas escolhas pode ser para a experiência dos alunos, que, segundo temos defendido, é a fonte por excelência da produção de sentidos, a base das relações formativas. Se tivesse o olhar situado no tempo dos programas, das avaliações e dos relatórios, Tiago teria deixado escapar a oportunidade áurea de compreender, por um indício bastante sutil, aspectos reveladores da real capacidade expressiva de seu aluno, interpretando o que via como mero erro. Foi por estar sensível o bastante ao cotidiano que o professor pode situar seu olhar no tempo da criança. Percebemos, portanto, que apenas saber o que fazer não basta. Nenhuma prescrição parece funcionar quando tomada literalmente. Se o professor não enxergar-se como pertencente à sua turma e deixar-se afetar por ela, pouco conseguirá.

Eis um saber-fazer que apenas o cotidiano escolar pode proporcionar ao professor: promover situações nas quais os alunos tenham seus sentidos e suas habilidades provocados pela experiência estética. Tal movimento só se revela possível quando o profissional busca, em sua própria prática, a presença de múltiplas formas de expressão. É ele que torna sensível o olhar e a escuta de seus alunos, aprendendo e ensinando sobre os sentidos possíveis do que é apreendido, as muitas maneiras de perceber a realidade e de tomar-se de encanto pelo mundo. Compreender os alunos como indivíduos portadores de histórias, experiências e relações diversas é um modo sensível e integrador de olhar para as práticas educativas. 


\section{Lições aprendidas: o professor como propositor de experiências}

Ressaltamos aqui alguns desdobramentos possíveis que o olhar estético para o cotidiano promove na prática do professor. Sem o intuito de concluir a temática, optamos por trazer, como considerações finais, lições aprendidas com os professores e suas experiências narradas.

Para compreender a subjetividade das experiências vividas no cotidiano pelos professores, é necessário ler as entrelinhas, perceber as razões de suas escolhas e ir ao encontro dos movimentos reflexivos da prática e da profissionalidade docente. Em tempo e espaço demarcados, com horas-aula a serem preenchidas com currículos, competências e habilidades definidas por outrem, o professor busca, ao experienciar, refletir e sentir aquilo que vive na escola, reencontrar sentido para a profissão e dar fôlego para sua formação.

Por fazer-se atento e por saber da dimensão estética de sua atuação, o professor compreende sua prática cotidiana evidenciando os conflitos da sala de aula, suas fragilidades, as dificuldades da docência, os caminhos possíveis e as estratégias pensadas para as situações a serem encaminhadas. Por intermédio desse processo, pode produzir textos narrativos que descrevem a ação, possibilitam refletir sobre ela e também sobre os próprios princípios e crenças. Podemos assim considerar, de acordo com Prado e Soligo (2005), a própria escrita de si e de sua prática como outro importante movimento formativo. Por isso, ao convidar as vozes dos professores Cristina, Márcia e Tiago para o diálogo, afirmamos a crença na formação estética que se alicerça no cotidiano da escola e que faz dos dilemas - e das reflexões decorrentes deles - mote para a ampliação de saberes e proposição de novas estratégias educativas.

A sensibilidade e a percepção estética são características percebidas nos professores que questionam sua prática e buscam enxergar seu cotidiano de maneira curiosa. Considerando que educar pressupõe atribuir sentido, acumular saberes que tornem possível uma vivência mais consciente e crítica em sociedade - atividade que implica ensinar e levar o indivíduo a aprender mais sobre si mesmo e sobre o meio que o envolve -, percebemos como é imprescindível pensar uma educação que preze pela experiência.

Tal qual o aprendiz e o artesão, sabemos que o aluno e o professor aprendem e ensinam, a si próprios e aos outros, sincronicamente. Como afirma Mattar (2010), o processo de aprendizagem é construído pelo aprendiz durante a sua jornada, mas não só por ele. Na realidade, o aprendiz se apropria do conhecimento em/ao se relacionar com os outros e com o seu meio. Esses outros, esses lugares, são o que constitui sua jornada. É nesse modo de ver e entender os processos educativos que 
reside a poética e a estética da educação, quando os caminhos, as potencialidades e as indagações pessoais são consideradas e constituem também a coletividade do espaço da escola.

Defender práticas de formação pautadas na cultura e nas experiências cotidianas não é mero exercício de desenvolvimento pessoal. É também modo de lançarmo-nos além da sala de aula, de ampliar perspectivas e saberes, difundindo modos de ser e de pensar a educação. Assim, viver e formar-se a partir das práticas do cotidiano não é um compromisso individual, mas com o mundo. É testemunho que materializa uma percepção única, e ao mesmo tempo múltipla, de atitudes, acontecimentos e encontros. Evidencia o sujeito histórico, social e cultural, possibilitando uma ampliação da imagem que se faz daquele que experiencia a educação sensível. Desvela o espaço da escola como palco de tensões e de relações negociadas, dialéticas e possíveis. O cotidiano, ao ser compreendido como lócus do conhecimento e da experiência estética, mostra-nos não só os padrões e as predominâncias, pois vai além das permanências, direcionando nossa atenção também para as mudanças, a presença e as ausências, escolhas e renúncias. É no cotidiano da escola que acontece o encontro entre o tempo e o espaço do conhecimento técnico com as sensibilidades dos sujeitos. Na aula, a cultura da infância, o regionalismo, as singularidades e histórias se entrecruzam e dão origem a novos e importantes saberes.

Avançando ainda mais na reflexão acerca da formação que ocorre no cotidiano da escola, importa registrar que, ao perceber-se como produtor de conhecimento e ao reconhecer a alternância de tempos e sentidos do espaço da escola quando contempladas intencionalmente as dimensões estéticas de seu trabalho, o professor age de forma propositiva (MATTAR, 2010). Isso significa que ele deixa de ser mero receptor e/ou transmissor de conteúdos para propor experiências mais amplas, que mobilizem a si próprio e aos seus alunos.

Ao utilizar o termo propositor, fazemos referência ao conceito utilizado por Lígia Clark e Hélio Oiticica em relação à atitude do artista como propositor de novas experiências, como posto em carta publicada em 1980:

Nós somos os propositores: somos o molde, cabe a você o sopro, o sentido da nossa existência. Nós somos os propositores: nossa proposição é o diálogo. Sós, não existimos. Estamos à sua mercê. Somos os propositores: enterramos a obra de arte como tal e chamamos você para que o pensamento viva através da ação. Nós somos os propositores: não lhe propomos nem o passado, nem o futuro, mas o agora. Experimentar um espaço sem avesso ou direito, frente ou verso, apenas pelo prazer de percorrê-lo, e dessa forma ele mesmo realiza a obra de arte (CLARK; GULLAR; PEDROSA, 1980, p. 23-24).

Tal concepção elucida a imagem de professor e de formação que observamos nas narrativas docentes: professor que intencionalmente fomenta e compartilha experiências sensíveis, chamando o outro ao diálogo e à reflexão acerca do vivido. 
Formação que prioriza a criação, a aproximação sensível com a cultura, em busca de caminhos possíveis e outras elaborações teóricas que se originem da escuta e do acolhimento das emergências cotidianas.

O professor propositor assume posição provocativa. Suas ações são planejadas para colocar o grupo de trabalho em movimento de forma ativa e reflexiva, suas ações propõem o debate, a autoria e a criação. É profissional que aponta a possibilidade de encantamento com a profissão, de modo responsável e consciente, uma vez que busca direcionar o olhar para a estética da docência, que se revela bela por estar sedimentada na interação entre os sujeitos, evidenciando uma relação ativa e participante com o conhecimento. É professor que, assim como dito por Nóvoa (2009), se constitui com e a partir do outro.

O professor, ele próprio fazendo-se permeável às delicadezas de seu cotidiano, atento às riquezas de sentido em suas relações com os alunos e dedicado ao aprendizado permanente de ser docente, possivelmente saberá encontrar, nas próprias reflexões e experiências, formas de propor uma vivência cotidiana repleta de estética e formação em sua sala de aula.

\section{Everyday aesthetics experience and production of knowledge in teacher training}

\section{Abstract}

It is taken as object of study and reflection, in this work, the possible articulation between everyday school activities and aesthetic experiences that enable a sensitive and integrative teacher training. From a historical-cultural perspective, it questions the separation between production of knowledge teaching, discussing the training of teachers and proposing this also happens in the school routine, which can be the stage of sensitizing and transforming experiences. To this end, it is stated that it is needed for the teacher an aesthetic attitude toward practice, analogous to the artisan that combines the technical expertise of his craft to the sensitive knowledge gathered from experience, aware of the subtleties of what he senses and permeable to charm, learning and teaching in the relationship with the other. Whereas in this way the school routine becomes an ideal site for producing knowledge on teaching that could not be built otherwise, we seek to demonstrate that this professor, perceiving students as having stories and singularities, may turn himself in proponent of meaningful experiences, potent to assist them in the production of meaning, in an authentically formative relationship.

Keywords: Aesthetic education. Everyday life. Teacher training. 


\section{Nota}

1 Esta narrativa e as que abrem as duas seções seguintes foram recolhidas dos volumes II e III do livro Pipocas pedagógicas: narrativas outras da escola, de Campos e Prado (2014, 2015). Pipoca pedagógica é o nome que vem sendo dado, pelo Grupo de Estudos e Pesquisas em Educação Continuada da Faculdade de Educação da Universidade Estadual de Campinas, para o gênero de narrativas curtas produzidas por professores sobre um acontecimento de seu cotidiano escolar, que carregam em si uma reflexão sobre a prática docente.

\section{Referências}

ALARCÃO, Isabel. Professores reflexivos em uma escola reflexiva. São Paulo: Cortez, 2010.

CAMPOS, Cristina Maria. Ratei! In: CAMPOS, Cristina Maria; PRADO, Guilherme do Val Toledo (Org.). Pipocas pedagógicas III: narrativas outras da escola. São Carlos: Pedro \& João, 2015. p. 27-28.

CLARK, Lygia; GULLAR, Ferreira; PEDROSA, Mário. Lygia Clark. Rio de Janeiro: Funarte, 1980.

DEWEY, John. Arte como experiência. São Paulo: Martins Fontes, 2010.

DUARTE JR., João-Francisco. O sentido dos sentidos: a educação (do) sensível. Curitiba: Criar, 2001.

FERNANDES, Márcia Cristina Benassi. Possibilidades para o ato de ler. In: CAMPOS, Cristina Maria; PRADO, Guilherme do Val Toledo (Org.). Pipocas pedagógicas II: narrativas outras da escola. São Carlos: Pedro \& João, 2014. p. 60-62.

FERREIRA, Luciana Haddad. Educação estética e prática docente: exercício de sensibilidade e formação. 2014. Tese (Doutorado em Educação) - Faculdade de Educação, Universidade Estadual de Campinas, Campinas, 2014.

FREIRE, Paulo. Política e educação. São Paulo: Cortez, 1993.

GERALDI, João Wanderley. A aula como acontecimento. São Carlos: Pedro \& João, 2010.

MATTAR, Sumaya. Sobre arte e educação: entre a oficina artesanal e a sala de aula. Campinas: Papirus, 2010.

NÓVOA, Antonio. Professores: imagens do futuro presente. Lisboa: Educa, 2009.

PINA, Tamara Abrão; SADALLA, Ana Maria Falcão de Aragão. Dilemas e saberes docentes: entrelaçando formação e tomadas de decisão cotidianas. In: VARANI, Adriana; FERREIRA, Cláudia Roberta; PRADO, Guilherme do Val Toledo (Org.). Narrativas docentes: trajetórias de trabalhos pedagógicos. Campinas: Mercado de Letras, 2007. p. 273-297.

PRADO, Guilherme do Val Toledo; SOLIGO, Rosaura. Porque escrever é fazer história: revelações, subversões, superações. Campinas: Átomo e Alínea, 2005.

RIBEIRO, Tiago. Não ta conseguindo ler, tio?? É sério???. In: CAMPOS, Cristina Maria, PRADO; Guilherme do Val Toledo (Org.). Pipocas pedagógicas III: narrativas outras da escola. São Carlos: Pedro \& João, 2015. p. 106-109. 
SÁ-CHAVES, Idália. A construção de conhecimento pela análise reflexiva da práxis. Coimbra: Fundação Calouste Gulbenkian e Fundação Para a Ciência e a Tecnologia, 2002.

SADALLA, Ana Maria F. Aragão. Com a palavra a professora: suas crenças, suas ações. São Paulo: Alínea, 1998.

SCHÖN, Donald. Educando o profissional reflexivo: um novo design para o ensino e a aprendizagem. Porto Alegre: Artes Médicas Sul, 2000.

TARDIF, Maurice. Saberes docentes e formação profissional. Rio de Janeiro: Vozes, 2002.

VIGOTSKI, Lev Semenovich. A construção do pensamento e da linguagem. São Paulo: Martins Fontes, 2001.

ZEICHNER, Kenneth. A formação reflexiva de professores: ideias e práticas. Lisboa: Educa, 1993. 